\title{
Os espaços líquidos da cibermídia
}

\author{
Lucia Santaella ${ }^{1}$ \\ PUC-SP \\ lbraga@pucsp.br
}

\begin{abstract}
Resumo: Explorando alguns aspectos históricos do desenvolvimento do ciberespaço, o artigo defende que este constui uma nova realidade, que marca o início de uma nova era cultural da humanidade. Com ela, emerge um novo tipo de leitor, o leitor imersivo, que se contrapõe ao contemplativo e ao movente, os dois perfis que predominaram até o final do século passado. Para este novo leitor, novos modos cognitivos entram em jogo.
\end{abstract}

Palavras-Chaves: ciberespaço, redes, leitor imersivo, mudança cultural

Cada vez mais crescentemente processos de comunicação são criados e distribuídos em forma digital legível no computador. Forma digital significa que quaisquer fontes de informação podem ser homonegeneizadas em cadeias de o e 1. Isso quer dizer que a mesma tecnologia básica pode ser usada para transmitir todas as formas de comunicação - seja na forma de textos, áudio ou vídeo - em um sistema de comunicação integrado, tal como aparece na internet.

\section{Como a internet funciona?}

Seu funcionamento depende não apenas do papel capital desempenhado pela informática e pelos computadores, mas da comunicação que se institui entre eles através da conexão em rede. As duas forças principais da informática, capacidade de armazenamento e processamento da informação multiplicam-se imensamente na medida em que as máquinas podem se beneficiar umas das outras. Na internet, a palavra "rede" deve ser entendida em uma acepção muito especial, pois ela não se constrói segundo princípios

\footnotetext{
${ }^{1}$ Lucia Santaella é professora titular da PUCSP com doutoramento em Teoria Literária na PUCSP, em 1973, e Livre-Docência em Ciências da Comunicação na ECA/USP, em 1993. É Diretora do CIMID, Centro de Investigação em Mídias Digitais, da PUCSP.
} 
hierárquicos, mas como se uma grande teia na forma do globo envolvesse a terra inteira, sem bordas nem centros. Nessa teia, comunicações eletrônicas caminham na velocidade da luz (300 mil kls/seg.), em um "tempo real”, podese dizer, no qual a distância não conta (Baylon e Mignot 1999: 376).

Quais são os componentes dessa teia? Ela se compõe de um número de dezenas de milhares de subredes, elas mesmas conectadas a redes chamadas de "espinhas dorsais" ou "redes federativas". Dentre as subredes, a mais empregada é a WWW (World Wide Web). A chave para conectar a rede está no seu conjunto subjacente de regras de comunicação ou protocolos. Para o usuário, a execução dos protocolos da rede é até certo ponto fácil, na medida em que não é necessário saber o que está por baixo da interface na tela, muito menos como funcionam os programas computacionais e a máquina em que esses programas são processados. Se o usuário não tiver muitas pretensões exploratórias, basta memorizar um plano técnico de indicações sumárias para que ele possa entrar na rede. É por isso que crianças de cinco anos já são capazes de se conectar a partir da memorização de uma pequena seqüência de ícones.

Por trás da tela, os protocolos têm um método de transmissão que é comum a muitos outros tipos de redes de dados, a comutação de pacotes. Isso significa que as transmissões digitais são quebradas em pequenas parcelas de dígitos, chamados de pacotes. Cada pacote tem bits adicionais, indicando os endereços na rede tanto da parte emissora quanto da parte receptora, a seqüência do número de cada pacote e um código para a verificação de erros. A vantagem disso é que muitas mensagens podem simultaneamente compartilhar de um único circuito. Por meio da informação dos endereços e das seqüências dos números, a mensagem é recondicionada no seu ponto de chegada. O futuro da tecnologia de comutação de pacotes será aumentar a velocidade de transmissão em várias ordens de magnitude através da fibra ótica. Deverá haver priorização de pacotes de modo que pacotes de voz e vídeo, que exigem entrega imediata, poderão receber tratamento preferencial 
sobre aplicações que aceitam algum atraso, como correio eletrônico (Straubhaar e LaRose 1997: 22).

O universo virtual das redes alastrou-se exponencialmente por todo o planeta fazendo emergir um universo paralelo ao universo físico no qual nossos corpos se movem. Assim sendo, como nos diz Nora (1997: 77), a internet converteu-se em uma mescla inacreditável de infraestruturas subsidiadas e dedicadas à investigação, de redes privadas de empresas, de centros de informação de todo tipo e um sem fim de grupos de discussão etc. Trata-se de uma estrutura associativa em cujo seio abrigam-se competidores econômicos selvagens. Por ser um gigante descentralizado, não conhece regras de jogo universais. Não tem donos, nem censores, apenas uma “netiqueta”.

Desde a imaginativa sugestão de Marcos Novac ([1991] 1993), o universo paralelo, que tem sua matriz na internet, que abriga megalópolis, ou bancos de dados comerciais, e uma infinidade de portais e sites de todas as espécies, vem sendo chamado de ciberespaço, um espaço informacional, cujas arquiteturas líquidas não têm fronteiras definidas.

\section{Onde está o ciberespaço?}

Não há resposta fácil para essa pergunta. “O ciberespaço é como $\mathrm{Oz}$ existe, chegamos a ele, mas não tem ubicação" (Stenger 1993: 54). De que se constitui isso que existe em um lugar sem lugar e que é, ao mesmo tempo, uma miríade de lugares? Consiste de uma realidade multidirecional, artificial ou virtual incorporada a uma rede global, sustentada por computadores que funcionam como meios de geração e acesso. Nessa realidade, da qual cada computador é uma janela, os objetos vistos e ouvidos não são nem físicos nem, necessariamente, representações de objetos físicos, mas têm a forma, caráter e ação de dados, informação pura. É certamente uma realidade que deriva em parte do funcionamento do mundo natural, físico, mas que se constitui de tráfegos de informação produzida pelos empreendimentos humanos em todas as áreas: arte, ciência, negócios e cultura (Benedikt 1993: 116). 
Como o ciberespaço se relaciona com a realidade virtual, com a visualização da informação, com as interfaces gráficas dos usuários, com as redes, com os meios de comunicação múltiplos, com a convergência das mídias, com a hipermídia, com a net arte? Ele se relaciona com todos, inclui a todos, pois tem a capacidade de reunir e concentrar todas esses tentáculos em um mesmo espaço rizomático, sem começo nem fim.

Nessa medida, o ciberespaço deve ser concebido como um mundo virtual global coerente, independente de como se acede a ele e como se navega nele. Tal qual uma língua, cuja consistência interna não depende de que os seus falantes estejam, de fato, pronuciando-a, pois eles podem estar todos dormindo, em um dado momento imaginário, o ciberespaço, como uma virtualidade disponível, independe das configurações específicas que um usuário particular consegue extrair dele. Além disso, há várias maneiras de se entrar no ciberespaço. Pelas animações sensíveis de imagens no monitor do vídeo controlado pelo mouse, passando pela tecnologia da realidade virtual que visa recriar o sensório humano tão plenamente quanto possível, até os eletrodos neurais diretos.

Benedikt (ibid.: 162) estabelece sete princípios para o design e a natureza do ciberespaço:

(a) O princípio da exclusão: duas coisas não podem ocupar o mesmo lugar ao mesmo tempo.

(b) O princípio da máxima exclusão, junto com a identidade máxima do objeto. Dado qualquer estado n-dimensional de um fenômeno e todos os valores - reais e possíveis - de $\mathrm{n}$ dimensões, eleger como dimensões extrínsecas - como espaço e tempo - aquele conjunto de (dois ou três ou quatro) dimensões que minimizarão o número de violações do princípio de exclusão.

(c) O princípio da indiferença. A realidade sentida de qualquer mundo depende do grau de sua indiferença quanto à presença de um usuário particular e de sua resistência ao desejo dele. 
(d) $\mathrm{O}$ princípio de escala. A velocidade máxima (de espaço) de movimento do usuário no ciberespaço é uma função inversa, monotônica da complexidade do mundo visível para ele.

(e) O princípio do trânsito. A distância entre dois pontos do ciberespaço deverá ocorrer fenomenicamente através de todos os pontos que intervêm nele, sem importar a rapidez (salvo quando se tratar de uma velocidade infinita). O viajante deve arcar com os custos proporcionais da distância percorrida.

(f) O princípio da visibilidade pessoal. Os usuários individuais no e do ciberespaço deveriam ser visíveis, de alguma forma não trivial, e em todo momento, a todos os demais usuários vizinhos, e os usuários individuais podem escolher por suas próprias razões se desejam ou não, e em que medida, ver qualquer usuário vizinho ou todos eles.

(g). O princípio da comunidade recomenda que os espaços virtuais sejam objetivados de maneira circunscrita por uma comunidade de usuários definida.

Quando Benedikt editou o seu livro antológico Ciberespaço. Primeiros Passos (1991), de onde as informações acima foram extraídas, as redes estavam engatinhando. É impressionante o poder premonitório dos prognósticos contidos nesse livro, pois foi só em 1993 que a WWW se difundiu mundialmente a partir da consolidação da língua franca da internet, a linguagem HTML (Hypertext Mark-up Language), baseada em vínculos hipertextuais entre palavras, e seus protocolos derivados. Logo depois, Marc Pesce inventou uma nova linguagem informática, a VRML (Virtual Reality Modelling Language).

\section{As interfaces do ciberespaço}

"Imaginem", dizia Pesce (apud Reid 1997: 171),

uma interface de internet onde as fontes de dados - livros, sons, vídeos, pudessem ser representados de maneira natural, como são no mundo real, 
com metáforas procedentes do mundo real. A gente pode recordar as metáforas do mundo real porque têm sentido. [...] Organizamos nossas vidas sensorialmente - pense em sua coleção de discos - e necessitamos transferir essa mesma técnica para a internet se, de fato, queremos usar a rede de acordo com todas as nossas capacidades.

Veio daí a idéia de criar uma interface sensorial na WWW, da qual procede a VRML, apresentada pela primeira vez em Orlando, no SIGGRAPH 1994, e imediatamente implementada pela Silicon Graphics, a empresa mais potente em infografia no planeta. Para operacionalizar as propostas de Pesce e seus seguidores, que já haviam criado um primeiro ambiente virtual telemático, o Labyrinth, a Silicon adquiriu o ambiente de programação Open Inventor , criado por Rick Carey e construiu o portal Web Space, especificamente desenhado para a nova linguagem. Assim surgiu a versão VRML 1.0 que teve grande impacto sobre os internautas interessados na transmissão de imagens, apesar de suas insuficiências, como, por exemplo, o caráter estático das imagens e sua incapacidade para incorporar o som. Em 1996, essas insuficiências foram superadas na versão 2.0 que se converteu prontamente no principal padrão da internet para a transmissão de imagens tridimensionais.

Com isso, as imagens podiam então se mover em cenários virtuais representáveis na própria rede, à maneira de desenhos animados no ciberespaço. Também era possível incorporar sons procedentes de tais imagens, o que possibilitou criar representações de sujeitos falantes nos lugares virtuais. Além disso, essas entidades virtuais, providas de sensores, reagiam aos movimentos e sons emitidos por outras imagens, mediante técnicas de vida artificial. Estava assim inventado o teatro virtual interativo que se desenvolveu vertiginosamente a partir de 1997 (Echeverría 2000: 9092).

Nessas alturas, os navegadores já estavam em plena ação e o Netscape incorporou rapidamente a VRLM 2.0. Embora tenha tentado lançar uma 
linguagem alternativa, a Microsoft acabou por incorporá-la ao Explorer. Com isso, uma linguagem ideográfica aparecia como uma nova linguagem para a rede. Com a VRLM surgiram os lugares virtuais nas redes e os avatares.

O termo "avatar" foi apropriado do sânscrito, referindo-se originalmente à noção indu de uma deidade que desce à terra em uma forma encarnada. Do mesmo modo, um usuário veste a identidade dessa entidade virtual para transitar em um mundo paralelo. Avatares são figuras gráficas que podem movimentar-se, atuar e interrelacionar-se com outras máscaras digitais em um mundo virtual tridimensional. Cada usuário que entra nesses ambientes virtuais pode criar seu próprio avatar, ao eleger uma máscara em um guarda-roupa digital disponível. Vestindo a pele de um avatar, o usuário pode teleportá-lo de sala a sala, controlar sua posição no quadro, fazê-lo dizer coisas e mesmo produzir efeitos de som e gestos animados pré-programados.

\section{O que é o ciberespaço}

Não há um consenso quanto ao sentido que se dá para o ciberespaço. Para alguns (ver, por exemplo, Batchen 1998: 273), trata-se estritamente de um sinônimo de realidade virtual (RV). Esta pode ser definida como um sistema informático capaz de criar um mundo simulado paralelo dentro do qual o usuário tem a impressão de, quando navega, estar manipulando seus objetos. Trata-se de um sistema que permite simular as percepções humanas, gerando um ambiente virtual que produz a sensação de realidade, na medida em que os objetos se movem de acordo com os movimentos e o ponto de vista do participante, todos controlados por computadores. Os recursos mais comuns para produzir esse tipo de experiência são os capacetes e as luvas de dados e um sistema informático que gera o ambiente virtual e transmite ordens do usuário através de um sistema de controle. Contemporaneamente, a cave, caverna digital, é um meio muito mais sofisticado para a criação de ambientes simulados que incorporam, em tempo real, o ponto de vista do participante (para mais informações sobre isso, ver Cantoni, no prelo). 
Embora a RV, de fato, se constitua no ponto mais alto da imersão de um participante no mundo simulado, o conceito de ciberespaço é mais amplo do que o de RV. Na verdade, a RV é apenas uma das dimensões possíveis do ciberespaço, talvez a mais sofisticada. Se é certo que não há um consenso sobre o sentido a ser dado a ciberespaço, a maioria dos autores concorda quanto ao fato de que, no seu sentido mais amplo, ele se refere a um sistema de comunicação eletrônica global que reune os humanos e os computadores em uma relação simbiótica que cresce exponencialmente graças à comunicação interativa. Trata-se, portanto, de um espaço informacional, no qual os dados são configurados de tal modo que o usuário pode acessar, movimentar e trocar informação com um incontável número de outros usuários. O ciberespaço inclui, portanto, todas as modalidades de uso que as redes possibilitam, de modo que a RV é apenas a extensão última desse processo até o ponto de produzir um grau de imersão sensória total no ambiente simulado.

Apesar do discenso, penso que a definição mais coerente de ciberespaço seria aquela que o considera como todo e qualquer espaço informacional multidimensional que, dependente da interação do usuário, permite a este o acesso, a manipulação, a transformação e o intercâmbio de seus fluxos codificados de informação. Assim sendo, o ciberespaço é o espaço que se abre quando o usuário conecta-se na rede. Por isso mesmo, esse espaço também inclui os usuários dos aparelhos sem fio, na medida em que esses aparelhos permitem a conexão e troca de informações. Conclusão, ciberespaço é um espaço feito de circuitos informacionais navegáveis. Um mundo virtual da comunicação informática, um universo etério que se expande indefinidamente mais além da tela, por menor que esta seja, podendo caber até mesmo na palma de nossa mão. 


\section{Imersão em espaços líquidos}

Também de acordo com o ponto de vista que defendo, entrar no ciberespaço é, sine qua non, imergir nesse espaço. A imersão é tanto mais profunda quanto mais o espaço é capaz de envolver o usuário tridimensionalmente, como é o caso da RV. Isso não significa, contudo, que a imersão se limita à RV. Há graus decrescentes de imersão. Assim, o limite máximo da imersão encontra-se na imersão perceptiva da RV.

Um outro grau de imersão é aquele que se dá através da telepresença. Esta ocorre quando a tecnologia de RV é conectada a um sistema robótico fisicamente presente em alguma locação à distância. "O usuário vê, toca e move-se pela locação fisicamente distante graças aos elos com os sensores dos robôs (câmaras, microfones, sensores de toque e etc.) e atuadores (braços de robôs)" (Biocca 1997: 203).

Há ainda o grau de imersão representativa, obtida nos lugares virtuais construídos pela linguagem VRML. Enquanto na RV, o participante tem a sensação de estar dentro, agindo no cenário virtual, na imersão representativa, o participante se vê representado no ambiente virtual, mas não está envolvido tridimensionalmente por ele. Um quarto grau de imersão, em ordem decrescente, é aquele que se dá quando o usuário se conecta na rede. Entrar na rede significa penetrar e viajar em um mundo paralelo, imaterial, feito de bits de dados e partículas de luz. Por isso mesmo, como quer Rheingold (1991: 101), o conceito de navegação transcende o tipo particular de tecnologia que se usa para a manipulação da informação. Transcende também a forma particular da informação. Assim sendo, é possível navegar:

(a) através de uma base de dados textuais;

(b) através de um elenco de imagens animadas;

(c) através de uma simulação virtual do mundo físico;

(d) ou via controle telerobótico, através de uma parte remota do mundo físico. 
Em todos esses casos, não obstante a diferença no grau de imersão de cada um deles, trata-se, ao fim e ao cabo, de navegação. É nesse sentido que tenho também defendido que o adjetivo "imersivo" qualifica um novo tipo de leitor, em contraposição a outros tipos de leitores que o precederam. Em um livro sob o título de Navegar no ciberespaço. O perfil cognitivo do leitor imersivo (Santaella 2004), baseado em pesquisa empírica, busquei caracterizar as novas formas de percepção e cognição que os atuais suportes eletrônicos e estruturas híbridas e alineares da hipermídia estão fazendo emergir. Que novas disposições, habilidades e competências de leitura estão aparecendo? Enfim, que novo tipo de leitor está surgindo no seio das arquiteturas líquidas das redes e conexões eletrônicas?

\section{O leitor imersivo}

Para isso, contrapus esse leitor, a que chamo de imersivo, a dois outros tipos que o antecederam: o leitor contemplativo e o leitor movente. Essa tipologia tomou por base as distintas habilidades sensoriais, perceptivas e cognitivas que estão envolvidas nos processos e no ato de ler, de modo a configurar modelos cognitivos de leitor. Isso resultou nos três tipos de leitores cada um apresentando um modelo cognitivo que lhe é próprio.

O primeiro, como já foi mencionado acima, é o leitor contemplativo, meditativo da idade pré-industrial, o leitor da era do livro impresso e da imagem expositiva, fixa. Esse tipo de leitor nasce no Renascimento e perdura hegemonicamente até meados do século XIX. O segundo é o leitor do mundo em movimento, dinâmico, mundo híbrido, de misturas sígnicas, um leitor que é filho da revolução industrial e do aparecimento dos grandes centros urbanos: o homem na multidão. Esse leitor, que nasce com a explosão do jornal e com o universo reprodutivo da fotografia e cinema, atravessa não só a era industrial, mas mantém suas características básicas quando se dá o advento da revolução eletrônica, era do apogeu da televisão. O terceiro tipo de 
leitor é aquele que começa a emergir nos novos espaços incorpóreos da virtualidade.

Embora haja uma sequencialidade histórica no aparecimento de cada um desses tipos de leitores, isso não significa que um exclui o outro, que o aparecimento de um tipo de leitor leva ao desaparecimento do tipo anterior. Ao contrário, não parece haver nada mais cumulativo do que as conquistas da cultura humana. O que existe, assim, é uma convivência e reciprocidade entre os três tipos de leitores, embora cada tipo continue, de fato, sendo irredutível ao outro, exigindo inclusive habilidades perceptivas, sensório motoras e cognitivas distintas.

Assim sendo, o navegador é também um leitor, na medida em que se entenda a palavra "leitor" como designando aquele que desenvolve determinadas disposições e competências que o habilitam para a recepção e resposta à densa floresta de signos em que o crescimento das mídias vem convertendo o mundo. Trata-se de um tipo especial de leitor, o imersivo, quer dizer, aquele que navega através de fluxos informacionais voláteis, líquidos e híbridos -- sonoros, visuais e textuais - que são próprios da hipermídia.

Não obstante o grande número de opções que hoje se abrem a esse novo tipo de leitor, os ambientes líquidos ciberespaciais codificaram-se em rotas e sítios sinalizados com uma organização interna que, nos serviços que disponibiliza, apresenta alguns tipos de comunicação já estratificados, tais como:

(a) O correio eletrônico que pode também conduzir a voz mais rapidamente do que a escrita que exige mais esforço.

(b) Os grupos de discussão que se constituem tanto nos foruns que congregam grupos reunidos em torno de interesses comuns, quanto nos grupos de discussão em tempo real, Internet Relay Chats.

(c) A busca de informações na internet que se tornou uma das vias privilegiadas para a pesquisa científica, para a publicação de revistas on line e 
para uma série inumerável de outros serviços de disponibilização de informações.

(d) $\mathrm{O}$ comércio e a publicidade eletrônicas que igualmente povoam o ciberespaço.

Esses ambientes deram origem a novas formas de socialização e agregação que vêm recebendo o nome de comunidades virtuais. Estas têm crescido e se diferenciado com uma tal intensidade a ponto de produzir o aparecimento de uma nova forma de cultura, a cultura do ciberespaço ou cibercultura (ver Lévy 2000, Lemos 2002, Costa 2002, Santaella 2003). Conforme tenho defendido, há algum tempo, trata-se de uma nova era cultural cuja complexidade tem atraído a sensibilidade dos artistas e desafiado o pensamento dos analistas da cultura e dos cientistas sociais. Enfim, trata-se de uma realidade intricada na qual estamos imersos e da qual não se pode escapar com subterfúgios saudosistas, nem simplesmente louvar com aplausos ingênuos.

\section{Referências bibliográficas}

Batchen, Geoffrey (1998). Spectres of cyberspace. Em The visual culture reader, Nicholas Mirzoeff (ed.). London and New York: Routledge, 273-278. Baylon C. e Mignot, X. (1999). La Communication, 2a. ed. aumentada. Nathan Université.

Benedikt, Michael (1991). El ciberespacio: algunas propuestas. Em Ciberespacio. Los Primeros Pasos, M. Benedikt (ed.), Pedro A. Gonzáles Caver (trad.). México: CONACYT/Sirius Mexicana, 113-206.

Biocca, Frank (1997). Realidade virtual: o extremo limite da multimídia. Em Comunicação na era pós-moderna, Monica Rector e Eduardo Neiva (eds.). Petrópolis: Vozes, 200-225.

Cantoni, Rejane (no prelo). Bodyarchitecture. Número especial Revista DeSignis, Los medios audiovisuales entre arte y tecnologia, Winfried Nöth (org.).

Costa, Rogério (2002). Cultura digital. São Paulo: Publifolha.

Echeverría, Javier (2000). Un mundo virtual. Barcelona: Devolsillo. Lemos, André (2002). Cibercultura. Tecnologia e vida social na cultura contemporânea. Porto Alegre: Sulinas.

Lévy, Pierre (2000). Cibercultura. São Paulo: Ed. 34. 
Nora, Dominique (1997). La conquista del ciberespacio, Carlos Gardini (trad.). Barcelona: Editorial Andrés-Bello.

Novac, Marcos ([1991] 1993). Arquitecturas líquidas en el ciberespacio. Em Ciberespacio. Los Primeros Pasos, M. Benedikt (ed.), Pedro A. Gonzáles Caver (trad.). México: CONACYT/Sirius Mexicana, 207-234.

Reid, Robert H. (1997). Architects of the web. New York: John Wiley. Rheingold, Howard (1991). Virtual Reality. London: Secker \& Warburg. Santaella, Lucia (2003). Culturas e artes do pós-humano. Da cultura das mídias à cibercultura. São Paulo: Paulus, $2^{\mathrm{a}}$. ed. 2004.

-------------(2004). Navegar no ciberespaço. O perfil cognitivo do leitor imersivo. São Paulo: Paulus.

Stenger, Nicole (1993). La mente es un arco iris con fugas. Em Ciberespacio. Los Primeros Pasos, M. Benedikt (ed.), Pedro A. Gonzáles Caver (trad.). México: CONACYT/Sirius Mexicana, 51-60.

Straubhaar, J. e LaRose, R. (1997). Communication media in the information society. Belmont: Wadsworth Publishing Company. 